\title{
Aplicação do modelo linear de mistura espectral para mapeamento de pastagens degradadas e solo exposto na Amazônia
}

\author{
Fabrício Assis LEAL ${ }^{*}$, Maila Pereira de ALMEIDA ${ }^{1}$ Glória da Silva Almeida LEAL ${ }^{1}$ \\ 1Universidade Federal do Acre, Campus Floresta, Cruzeiro do Sul, AC, Brasil. \\ (ORCID: *; 0000-0002-6538-3415; 0000-0002-0381-1584) \\ *E-mail: fabricioassisleall@gmail.com (ORCID: 0000-0001-8522-0114)
}

Recebido em 09/12/2019; Aceito em 14/04/2020; Publicado em 24/04/2020.

\begin{abstract}
RESUMO: Este trabalho se ocupou no mapeamento e quantificação de pastagens degradadas/solo exposto em propriedades rurais de São Félix do Xingu/PA, em descobrir agrupamentos espaciais para taxas de pastagens degradadas, além de descrever o perfil das propriedades que estavam inseridas nestes agrupamentos. Foram utilizadas cenas do satélite Landsat 8 em 2017, classificadas para obtenção de áreas de pastagens. Depois foi utilizada análise de mistura espectral para obtenção da fração solo. Essa fração solo foi classificada e a primeira classe representou as áreas de pastagens degradadas/solo exposto. Essas áreas foram intersectadas com as propriedades rurais e depois classificadas em relação as taxas de pastagens degradadas/solo exposto. Sequencialmente as propriedades foram agrupadas espacialmente por meio de análise hot spot. A área total de pastagens em 2017 representou 49,8\%, já as áreas de pastagens degradadas/solo exposto somaram 21.621 hectares $(2,7 \%)$ e tiveram presentes em 3.643 (64\%) das propriedades rurais (5.691), sendo que 3.004 delas possuíam tamanho de até 500 ha, sendo caracterizadas como pequenas propriedades. Foram três os agrupamentos hot spot encontrados que concentraram 982 propriedades rurais. Dessas 982 propriedades, 878 delas $(89,4 \%)$ também estavam no grupo de até 500 ha. As pastagens degradadas e solo exposto estavam predominantemente concentradas nas pequenas propriedades rurais.
\end{abstract}

Palavras-chave: análise espacial; imagem fração-solo; pecuária.

\section{Linear spectral unmixing for mapping degraded pastures and bare soil in the Amazon}

\begin{abstract}
This work focused on the mapping and quantification of degraded pastures / bare soil in rural properties of São Félix do Xingu/PA, and in discovering spatial clusters for degradation rates, and describing the profile of the properties that were inserted in these clusters. We used scenes from the Landsat 8 satellite in 2017, classified to obtain pasture areas. Then spectral mixture analysis was used in the images to obtain the soil fraction. This fraction was classified and the first class represented the degraded pasture/exposed soil areas. These areas were intersected with the farms and then classified for degraded pasture/exposed soil rates. Sequentially the properties were spatially grouped by hot spot analysis. The total pasture area in 2017 represented $49.8 \%$, while degraded pasture / exposed soil areas totaled 21,621 hectares $(2.7 \%)$ and were present in 3,643 (64\%) of rural properties $(5,691)$, and 3,004 of them had a size of up to 500 ha, being characterized as small properties. There were three hot spot clusters found that concentrated 982 rural properties. Of these properties, 878 of them (89.4\%) were also in the group of up to 500 ha. Degraded pastures/exposed soil were predominantly concentrated on small farms.
\end{abstract}

Keywords: Spatial analysis; soil-fraction image; livestock.

\section{INTRODUÇÃO}

O Brasil é considerado o segundo maior produtor e o maior exportador mundial de carne bovina. Toda produção brasileira tem como base as pastagens, por ser o meio mais econômico e prático para produção e oferta de alimentos para os bovinos (DIAS-FILHO, 2014). De acordo com Ferraz e Felício (2010), as pastagens desempenham papel fundamental por garantir baixos custos de produção, sendo essa característica potencializada pelas condições climáticas e extensão territorial do país. Tais condições fazem com que o Brasil tenha um dos menores custos de produção de carne do mundo.
Embora sejam peculiaridades consideráveis, alguns costumes ainda contribuem para criar uma tradição de baixo investimento no uso de tecnologia e de insumos na formação e no manejo de grande parte das pastagens. Como consequência deste cenário cita-se a alta incidência de pastagens degradadas no país, bem como o rótulo que a pecuária desenvolvida a pasto é improdutiva e danosa ao meio ambiente (DIAS-FILHO, 2016).

Em relação a parte ambiental que envolve as pastagens, a conversão da vegetação nativa para implantação de áreas destinadas a pecuária tem sido um dos principais vetores do desmatamento na Amazônia (KAWAKUBO et al., 2013, 
MELO; ARTAXO, 2017). Dos estados que compreendem a Amazônia Legal (AML), o estado do Pará se destaca, desde 2006, como líder do ranking dos estados que mais desmataram na AML, com $267.393 \mathrm{~km}^{2}$ desmatados, correspondendo a 21,4\% de seu território (INPE/PRODES, 2018). O estado também se destaca como o segundo colocado em produção bovina na AML, que de acordo com a última divulgação em 2018 possuía 20.628.651 bovinos, o que significou $9,7 \%$ da produção nacional (IBGE/PPM, 2018).

Tais destaques, tanto no desmatamento quanto na produção bovina, refletiram em vários municípios do estado, principalmente em São Félix do Xingu (SFX). Não eventualmente, SFX suporta a maior concentração bovina do Brasil, liderando este ranking desde 2001, quando atingiu produção de mais um milhão de cabeças. Contudo, desde 2010 registra a impressionante marca de mais dois milhões de cabeças, com último registro em 2018 somando 2.256 .734 bovinos. Tal produção significou $11 \%$ dos bovinos no estado e $1 \%$ da produção nacional (IBGE/PPM, 2018). Não há outro município que produza tanto quanto SFX.

Desta forma, SFX se destaca como importante produtor bovino do país e, igualmente, como o município que mais desmatou na AML, onde em 2018 registrou $18.734 \mathrm{~km}^{2}$ desmatados (22,2\% do seu território). Este cenário de altas taxas de desmatamento ficou em evidência no município nesta última década. Tal fato ocorreu como consequência do modo de produção bovina implantado no município, essencialmente a pecuária extensiva, considerada ineficiência ao longo do tempo.
Todavia esse sistema de produção, quando associado a práticas inadequadas de manejo, pode causar degradação de pastagens ou condução de processos de degradação (DIASFILHO, 2011). Diante disto, esta pesquisa teve como objetivos mapear e quantificar pastagens degradadas e solo exposto em propriedades rurais de São Félix do Xingu/PA, verificar onde ocorreram os agrupamentos espaciais para as taxas de degradação e descobrir qual perfil de tamanho de propriedades rurais havia, predominantemente, nesses agrupamentos.

\section{MATERIAL E MÉTODOS}

\subsection{Localização da área de estudo}

O estudo foi realizado em São Félix do Xingu (SFX), estado do Pará, em específico na parte norte do município, numa região denominada área de consolidação II (AC-II), que envolve $16.288 \mathrm{~km}^{2}$ e concentra a maior parte $(74 \%)$ das propriedades rurais do município. A denominação AC-II foi inicialmente prevista pelo Zoneamento Ecológico Econômico das Zonas Leste e Calha Norte do estado do Pará (ZEE, 2010). A AC-II foi objeto no passado de projetos de colonização e de processos de ocupação espontânea em áreas públicas da União.

O município de SFX possui 124.763 habitantes, com densidade demográfica de $1,1 \mathrm{hab} / \mathrm{km}^{2}$. Apresenta área territorial de $84.213 \mathrm{~km}^{2}$, altitude média entorno de 200 metros e está localizado entre os paralelos $5^{\circ} 0^{\prime} 0^{\prime \prime}$ a $10^{\circ} 0^{\prime} 0^{\prime \prime}$ de latitude sul e entre os meridianos $50^{\circ} 0^{\prime} 0^{\prime \prime}$ a $54^{\circ} 0^{\prime} 0^{\prime \prime}$ de longitude oeste (Figura 1).

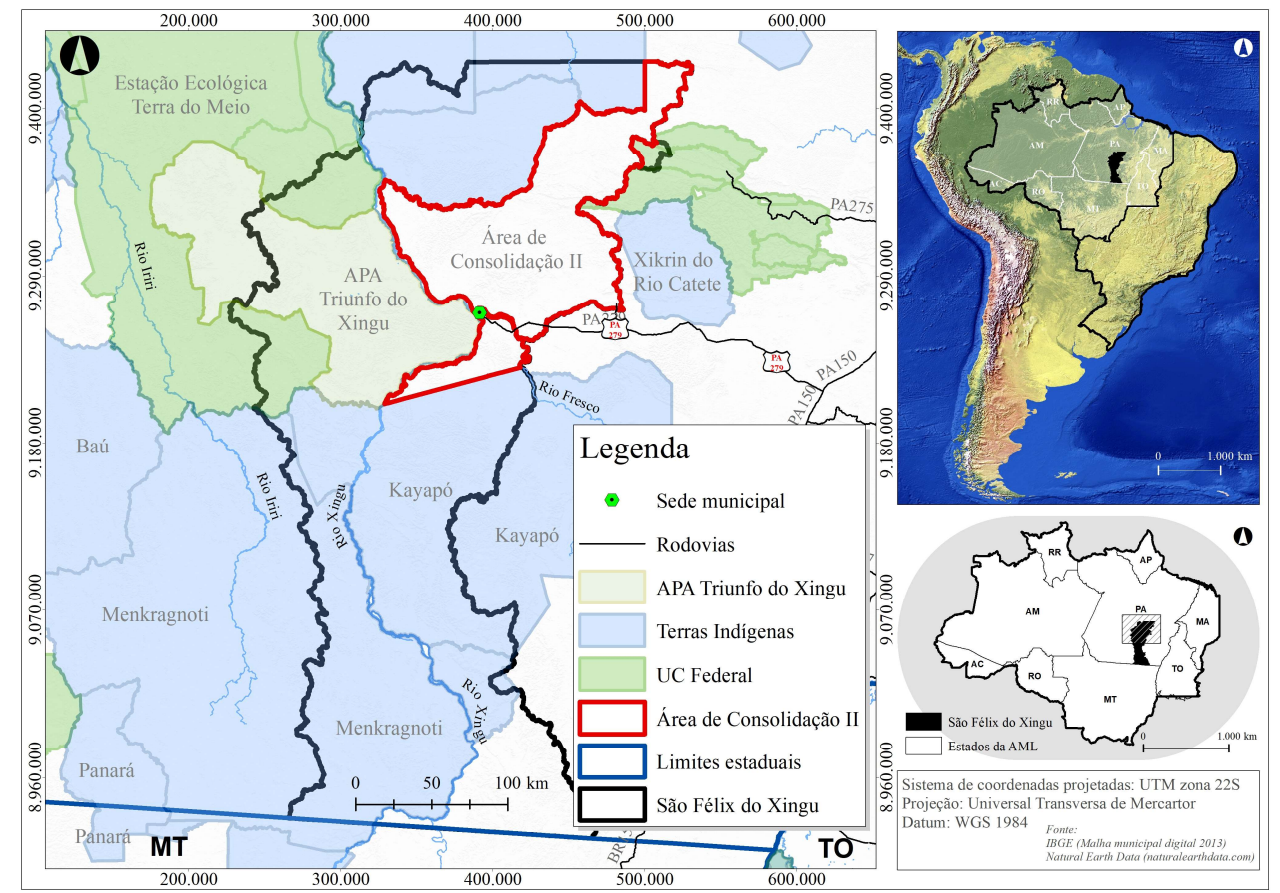

Figura 1. Localização da área de estudo denominada AC-II, em SFX, bem como um mosaico de áreas protegidas. Em que: UC = Unidade de conservação, APA = Área de proteção ambiental.

Figure 1. Location of the study area called AC-II in SFX, as well as a mosaic of protected areas. Where: UC $=$ Conservation Unit, APA $=$ Environmental Protection Area.

\subsection{Download das cenas, conversão radiométrica (toa)} e mosaico das cenas

Foram utilizadas imagens oriundas do sensor OLI (Operational Land Imager) do satélite Landsat 8 para o ano de
2017. Ao todo foram utilizadas quatro cenas $(225 / 65$, $225 / 64,224 / 65,224 / 64)$, com critério máximo de $10 \%$ de cobertura de nuvens. As cenas da órbita 225 foram do dia 20/07 e as cenas da órbita 224 foram do dia 29/07. O 
download foi realizado no sítio eletrônico do Serviço Geológico dos Estados Unidos (USGS, Earth Explore).

Após o download das cenas foi realizada a conversão radiométrica, que envolve a transformação de valores de números digitais (ND) para valores físicos de reflectância, no topo da atmosfera (TOA). Há abordagens que nem sempre é necessário realizar a calibração radiométrica, porém, em estudos que envolvem comparação e análise do comportamento espectral de determinado alvo é fundamental que se realize esta conversão (COSTA, 2017).

Esta conversão necessitou antes de uma conversão intermediária, onde os números digitais (DN) de cada banda foram convertidos para valores físicos de radiância (Watts $m$ $\left.{ }^{2} . \operatorname{srad}^{-1} \cdot \mu m^{-1}\right)$. Para esta conversão, cada banda espectral foi submetida a equação 1 abaixo, conforme proposto por Chander et al. (2009).

$$
\operatorname{Radiância}(L \lambda)=(\text { Gain } \times \text { Band })+\text { Bias }
$$

em que: Radiância $(\mathrm{L} \lambda)=$ Watts $\mathrm{m}^{-2} \cdot \mathrm{srad}^{-1} \cdot \mu \mathrm{m}^{-1} ;$ Gain $=$ fator multiplicativo reescalonado para a banda espectral específica; Band = banda espectral em números digitais $(\mathrm{DN}) ;$ Bias = fator aditivo relacionado para a banda espectral específica.

Os parâmetros acima foram encontrados e obtidos nos metadados das imagens, assim que o download, de cada banda, foi concluído. Após obtenção dos valores físicos de radiância (Watts $\mathrm{m}^{-2} . \mathrm{srad}^{-1} \cdot \mu \mathrm{m}^{-1}$ ), cada banda espectral foi convertida para reflectância no topo da atmosfera (TOA), conforme preconizado por Chander et al. (2009). A equação 2 abaixo exemplifica a conversão final.

$$
\text { Reflectância }(\rho)=\frac{\pi \times L \lambda \times d^{2}}{E S U N_{\lambda} \times \cos S}
$$

em que: Reflectância $(\varrho)$ = reflectância no topo da atmosfera com correção do ângulo solar (razão, sem unidade); $L \lambda=$ radiância espectral no sensor; $\mathrm{d}=$ distância Terra-Sol em unidades astronômicas; ESUN $\lambda$ = irradiância espectral solar exoatmosfera; $\cos \theta=$ zênite do ângulo solar (radianos).

Ao final desses processos todas as cenas (224/64, 224/65, 225/64 e 225/65), da imagem de 2017, ficaram disponíveis para a composição de bandas e mosaico. Após a elaboração do mosaico foi realizado o recorte conforme o limite vetorial da AC-II (Figura 1). Este processo eliminou áreas no mosaico que não foram analisadas e nem foram objetos de estudo.

\subsection{Mapeamento de uso do solo}

Após a etapa anterior, o mosaico recortado foi submetido ao mapeamento de uso do solo usando a classificação não supervisionada, por meio do algoritmo Iso Cluster Unsupervised Classification (NASCIMENTO et al., 2016). Este método é uma classificação não supervisionada, em que o operador não interfere no agrupamento das classes.

Inicialmente adotou-se 15 classes, porém foi realizada uma fusão entre elas deixando apenas duas classes de interesse em definitivo: "Pastagens" e "Outros usos". A classe "Pastagens" envolveu todos os tipos de pastagens encontradas na área de estudo, em diversos estágios de desenvolvimento. Já a classe "Outros usos" houve a inclusão de todos os outros usos do solo mapeados, conforme classificação preconizada por Almeida et al. (2016).
Para o agrupamento mencionado de classes foi utilizada a interpretação visual nas imagens originais e a edição manual por meio da ferramenta Reclassify (Spatial Analyst) do ArcGis ${ }^{\circledR}$. Ao final desse processo de unificação das classes foi obtida a imagem classificada referente ao ano de 2017, com as classes "Pastagens" e "Outros usos" quantificadas.

\subsection{Mapeamento de pastagens degradadas e solo exposto utilizando modelo linear de mistura espectral (MLME)}

Para realizar esta análise foi necessário selecionar endmembers (pixels puros) para solo, vegetação e água/sombra (YUE et al., 2019; SHIMABUKURO; SMITH, 1995; 1991). Essa seleção de endmembers foi realizada por meio do mosaico, em que após a identificação e seleção dos endmembers de cada fração (solo, vegetação e água/sombra) foram obtidas as estatísticas de cada conjunto desses, sendo elas: valor máximo, médio, mínimo e desvio padrão. Também foram obtidos os comportamentos espectrais médios para cada fração (conjunto de pixels).

Essas estatísticas foram gravadas e registradas para cada fração como arquivo do tipo roi (region of interest). Estes arquivos reuniram as estatísticas mencionadas anteriormente e foram indispensáveis para a análise de mistura espectral (MLME) (SHIMABUKURO; PONZONI, 2017). Após a obtenção dos endmembers e suas estatísticas foi utilizado o MLME, por meio do software ENVI. Para este processo foram utilizadas três bandas, com a seguinte composição de cor: banda $7(\mathrm{R})$, banda $5(\mathrm{G})$, banda $6(\mathrm{~B})$. Ao final foram geradas quatro imagens fração, uma para cada fração (vegetação, solo e água/sombra) e uma imagem de erro RMS (root means square). Como o objetivo do trabalho foi mapear solo exposto e pastagem degradada foi utilizada apenas a imagem fração solo (YUE et al., 2019).

Para selecionar e mapear as áreas de pastagens degradadas e solo exposto, os pixels da imagem fração solo foram classificados utilizando a classificação Natural Breaks (Jenks) (LEAL et al., 2019a; CHEN et al., 2013), em um processo onde os pixels foram distribuídos em 10 classes. A primeira classe dessa distribuição contemplou a classe de solo exposto e pastagens degradadas. Já as demais classes foram aquelas com quantidades de cobertura vegetal superiores a primeira e, desta forma, não foram utilizadas.

Para facilitar o processo de identificação de pastagens degradadas e solo exposto citado anteriormente, além da interpretação visual e da classificação da imagem fração solo supracitada, foram também consideradas a imagem classificada de 2017 e o índice de vegetação pela diferença normalizada (NDVI), obtido na mesma imagem (ROUSE et al., 1973). Essas análises em conjunto, envolvendo os recursos citados, foram capazes de garantir que apenas as áreas de pastagens degradadas e solo exposto fossem efetivamente selecionadas.

Depois destes processos, a primeira classe foi isolada e convertida para o formato shapefile. Este arquivo contendo as áreas de pastagens degradadas e solo exposto foi intersectado com o arquivo shapefile das propriedades rurais do SICAR (Sistema Nacional de Cadastro Ambiental Rural), com o objetivo de avaliar o perfil das propriedades rurais, em relação as taxas de pastagens degradadas e solo exposto. As propriedades foram classificadas conforme as taxas encontradas (\%) e também conforme seu tamanho (ha), sendo as classes das taxas de pastagens degradadas e solo 
exposto: 0 a 10; 10,1 a 20; 20,1 a 30; 30,1 a 40; 40,1 a 50; 50,1 a $60 ; 60,1$ a $70 ; 70,1$ a $80,80,1$ a $90 ; 90,1$ a $100 \%$; e as classes de tamanho das propriedades foram distribuídas em amplitudes a cada 500 hectares, sendo: 0 a $500 ; 501$ a 1.000 ; 1.001 a $1.500 ; 1.501$ a $2.000 ; 2.001$ a $2.500 ; 2.501$ a 3.000 ; 3.001 a 3.500; acima de 3.501 ha. As propriedades com área igual ou maior que 3.501 ha foram classificadas nessa última classe.

\subsection{Análise espacial de agrupamento das taxas de} pastagens degradadas para as propriedades rurais

Para entender melhor a dinâmica das propriedades rurais na AC-II, especialmente em relação as taxas de pastagens degradadas encontradas, foi realizada análise espacial de agrupamento hot spot utilizando as taxas (\%) como variável, e as propriedades rurais como objetos espaciais de agrupamento (LEAL et al., 2019b).

Essa análise serviu para indicar espacialmente locais onde ocorreram maior concentração de taxas de pastagens degradadas e solo exposto (bot spot), bem como menor concentração dessas taxas (cold spot). Neste processo também foi possível identificar regiões não significativas para o agrupamento espacial.

Para realizar esta análise foi necessário antes submeter os dados a um processo denominado de autocorrelação espacial. Este processo indicou a distância máxima onde os agrupamentos das propriedades rurais, para a variável "taxas de pastagens degradadas e solo exposto", foram mais pronunciados (TIAN; SUN, 2018). Essa distância foi fundamental para a análise espacial de agrupamento hot spot e adveio da ferramenta Incremental Spatial Autocorrelation, do ArcGis $^{\circledR}$ (LEAL et al., 2019b).

Ao final deste processo foi elaborado um mapa com a distribuição espacial dos agrupamentos encontrados, para a variável taxas, bem como foi realizado resumo descritivo das propriedades rurais que estavam contempladas nas regiões hot spot, com altas taxas de pastagens degradadas e solo exposto, com probabilidade igual ou superior a $95 \%$.

\section{RESULTADOS}

\subsection{Mapeamento do uso do solo}

Os resultados do mapeamento da dinâmica de uso do solo apontaram que a intensidade das mudanças ocorridas na AC-II foi especialmente considerável. Até 2017 um total de $8.111 \mathrm{~km}^{2}$ foram convertidos em áreas de pastagens (Figura 2) e corresponderam a $49,8 \%$ da área total $\left(16.288 \mathrm{~km}^{2}\right)$. Essa transformação foi compatível com o aumento de bovinos no município, pois em 2018, SFX já registrava 2.256.734 animais. Vale ressaltar que em 1980, 1990, 2000 e 2010, SFX registrou produção de 22.534, 34.637, 682.407 e 2.022 .366 animais, respectivamente (IBGE/PPM, 2018).

É possível notar na Figura 2, que a transformação da paisagem ocorreu predominantemente devido ao aumento da pecuária em SFX. Essa transformação teve início a partir de 2000, quando SFX registrou 682.407 bovinos e desde então a produção pecuária no município nunca mais ficou abaixo de um milhão de cabeças, até que em 2010 atingiu 2.022.366 bovinos. Após esse registro, SFX apresentou máxima produção em 2013 (2.282.445 bovinos) e depois estabilizou com pequenas oscilações: 2014 (2.213.310), 2015 (2.222.949), 2016 (2.200.338), 2017 (2.240.496) e 2018 (2.256.734) (IBGE/PPM, 2018).

\subsection{Pastagens degradadas e solo exposto}

Por meio do modelo linear de mistura espectral (MLME), a imagem fração solo foi obtida e posteriormente classificada para obter o mapeamento e a quantificação das áreas de pastagens degradadas e solo exposto. $\mathrm{O}$ intervalo de classe que resultou no mapeamento foi entre -2,9 a -1,1. Essa classe reuniu as pastagens degradadas e o solo exposto e ao todo foram quantificados 21.621 hectares (Figura 3).

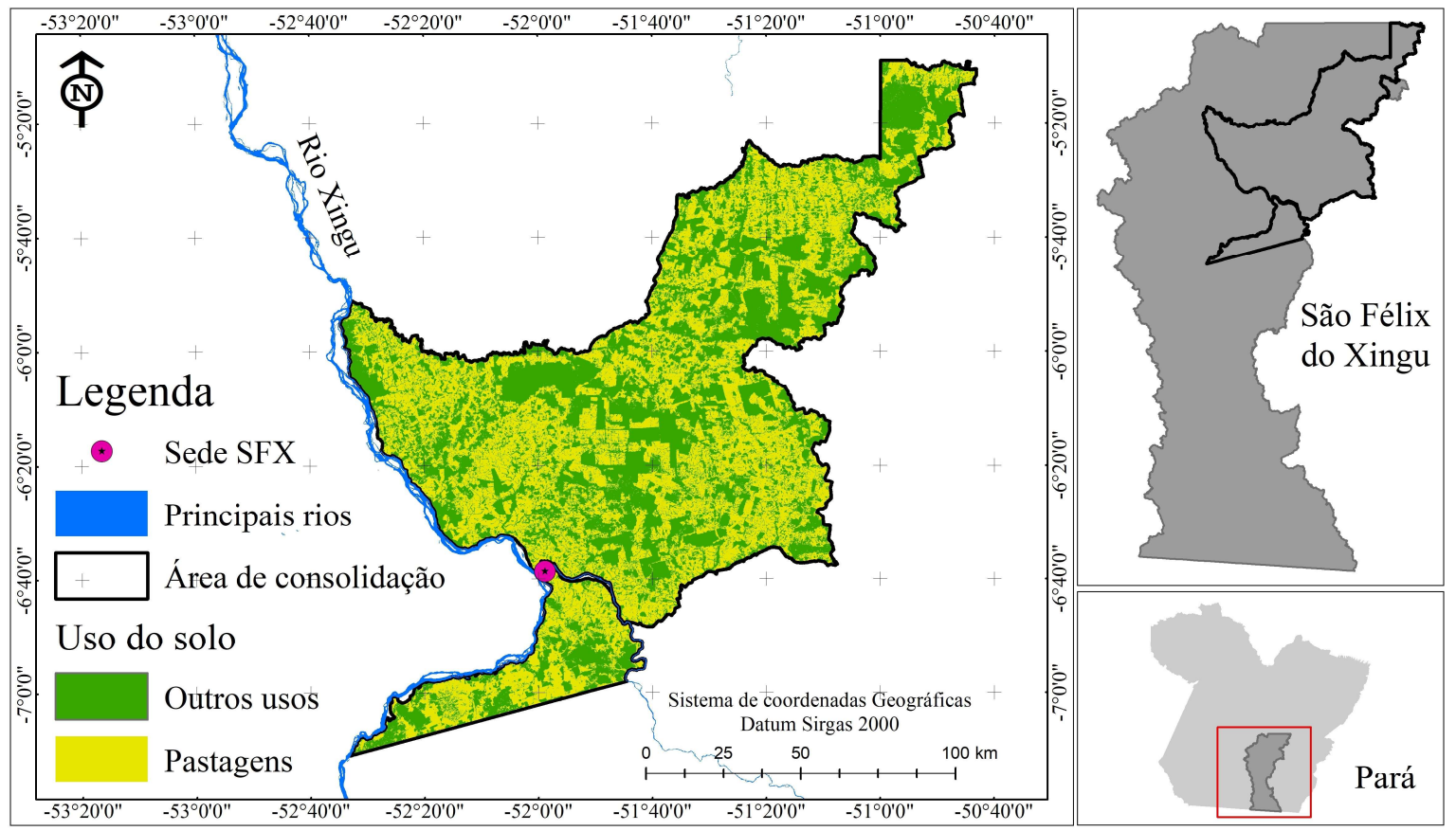

Figura 2. Resultado da classificação que mapeou o uso do solo para a AC-II, em 2017.

Figure 2. Result of the classification that mapped land use for AC-II in 2017. 


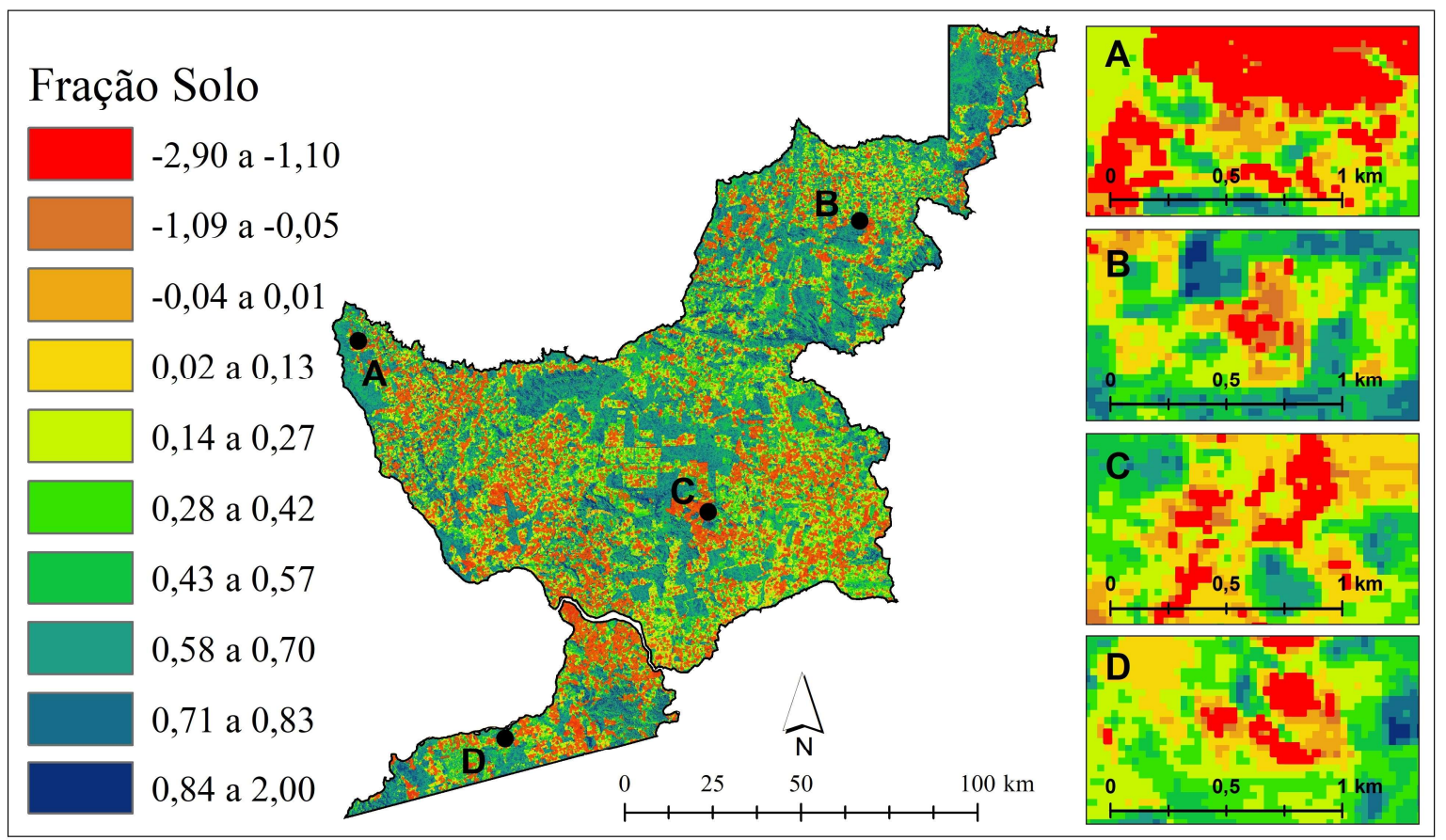

Figura 3. Imagem fração solo classificada, em que a primeira classe dessa distribuição representou as áreas de pastagens degradadas e solo exposto.

Figure 3. Image classified soil fraction, where the first class of this distribution represented degraded pastures and exposed soil.

Alternativamente, em um processo de verificação das áreas de pastagens degradadas e solo exposto mapeados (Figura 3) foram também considerados, juntamente com a imagem fração solo, o NDVI e a imagem classificada de 2017 (Figura 2).

Ao comparar as áreas de pastagens degradadas e solo exposto com o NDVI, a classificação de 2017 e o mosaico, foi possível notar que essa sobreposição foi relevante, pois notou-se que essas áreas correspondiam espacialmente em locais com baixa quantidade de vegetação na imagem NDVI, bem como coincidiam geograficamente com as áreas de pastagens mapeadas na classificação de 2017.

$\mathrm{Na}$ Figura 4 é possível notar dois pontos aleatórios utilizados para exemplificar o método de verificação adotado, para definição da amplitude de classe do mapeamento de pastagem degradada e solo exposto, nas imagens fração solo, NDVI, na classificação em 2017 e no mosaico.

Em todos os quadros da Figura 4, os limites em vermelho representaram a delimitação das áreas de solo exposto e pastagem degradada, após a definição da amplitude da classe utilizada $(-2,9$ a -1,1). Percebe-se que na imagem NDVI, os limites se sobrepõem às áreas com baixíssima vegetação (ver escala de vegetação no mapa), bem como também se sobrepõem às áreas classificadas como pastagem na imagem classificação de 2017, o que corrobora com o mapeamento realizado por meio do MLME, totalizando 21.621 hectares $(2,7 \%)$.

Os dados obtidos sobre as taxas de pastagens degradadas e solo exposto foram importantes para conhecer e comparar o perfil de propriedades rurais na AC-II. Assim, essas propriedades foram distribuídas em classes de tamanho de área, bem como em classes percentuais de taxas de pastagens (Tabela 1). Considerando as classes de tamanho das propriedades, conforme os resultados apresentados na Tabela 1, ressalta-se que das propriedades pertencentes ao SICAR na AC-II (5.691), 64\% delas (3.643) possuíam algum percentual de taxa de solo exposto e pastagem degradada, com diferentes percentuais.

Do total de propriedades encontradas (3.643), com algum nível de solo exposto e pastagem degradada, 82,5\% (3.004) delas se encontravam em propriedades rurais com tamanho de até 500 ha.

\subsection{Análise espacial de agrupamento das taxas de pastagens degradadas e solo exposto}

Objetivando o mapeamento de agrupamento das propriedades rurais, em relação às taxas de pastagens degradadas e solo exposto, foi realizada a análise hot spot. Nessa análise a distância de $10.371 \mathrm{~m}$ foi onde ocorreu o agrupamento mais pronunciado, para as taxas de pastagens degradadas e solo exposto, conforme índice de Moran 0,0639 (p-value < 0,0001) (MORAN, 1950).

No cálculo efetuado para agrupamento, a soma local para uma propriedade e os seus vizinhos foi comparada proporcionalmente à soma de todas as propriedades. Quando a soma local foi muito diferente da soma local esperada e essa diferença foi demasiadamente grande, resultou num valor zscore estatisticamente significativo para hot spot (DIAS et al., 2016).

De acordo com Rocha e Henriques (2014), depois de calculados, os resultados podem variar entre valores positivos e negativos. Quando os valores de z-score são positivos, e quanto maior for o valor, maior é a aglomeração de valores de hot spot (zonas quentes).

Quando os valores de z-score são negativos, e quanto menor for o valor, maior é a aglomeração de valores de cold spot (zonas frias). Na Figura 5, a seguir, é possível notar os agrupamentos formados em relação às taxas de pastagens degradadas e solo exposto, bem como as probabilidades dos agrupamentos. Foi possível notar ainda propriedades rurais que possuíram índice local de Moran (MORAN, 1950), com probabilidade de $99 \%$, 95\% e 90\%, tanto para áreas com altas 
Leal et al.

taxas de pastagens degradadas e solo exposto (hot spot), como para áreas com baixas taxas (cold spot). As cores quentes significaram agrupamentos estatisticamente significativos, sendo que todas as propriedades com probabilidade igual ou maior que $95 \%$ foram consideradas hot spot na AC-II.

A análise de agrupamento hot spot concentrou 982 propriedades com probabilidade igual ou maior que 95\%. Essas propriedades rurais foram quantificadas e qualificadas em classes de tamanho e em classes percentuais de pastagens degradadas e solo exposto (Tabela 2). Dessas 982 propriedades consideradas hot spot, cerca de $89,4 \%$ (878) se encontravam em propriedades rurais com até 500 ha. Dessas propriedades com até 500 ha (878), 91,3\% delas (802) possuíam pelo menos até $10 \%$ de taxa de pastagem degradada e solo exposto, dentro dos seus limites. Quando consideramos o percentual até $40 \%$, o total de propriedades rurais subiu para 975 . Isso significou dizer que 99,3\% das propriedades mapeadas com solo exposto e pastagem degradada estão concentradas em classes com até $40 \%$ de pastagem degradada e solo exposto. A porcentagem é bastante expressiva de propriedades, porém com pouca representação de propriedades consideradas grandes.
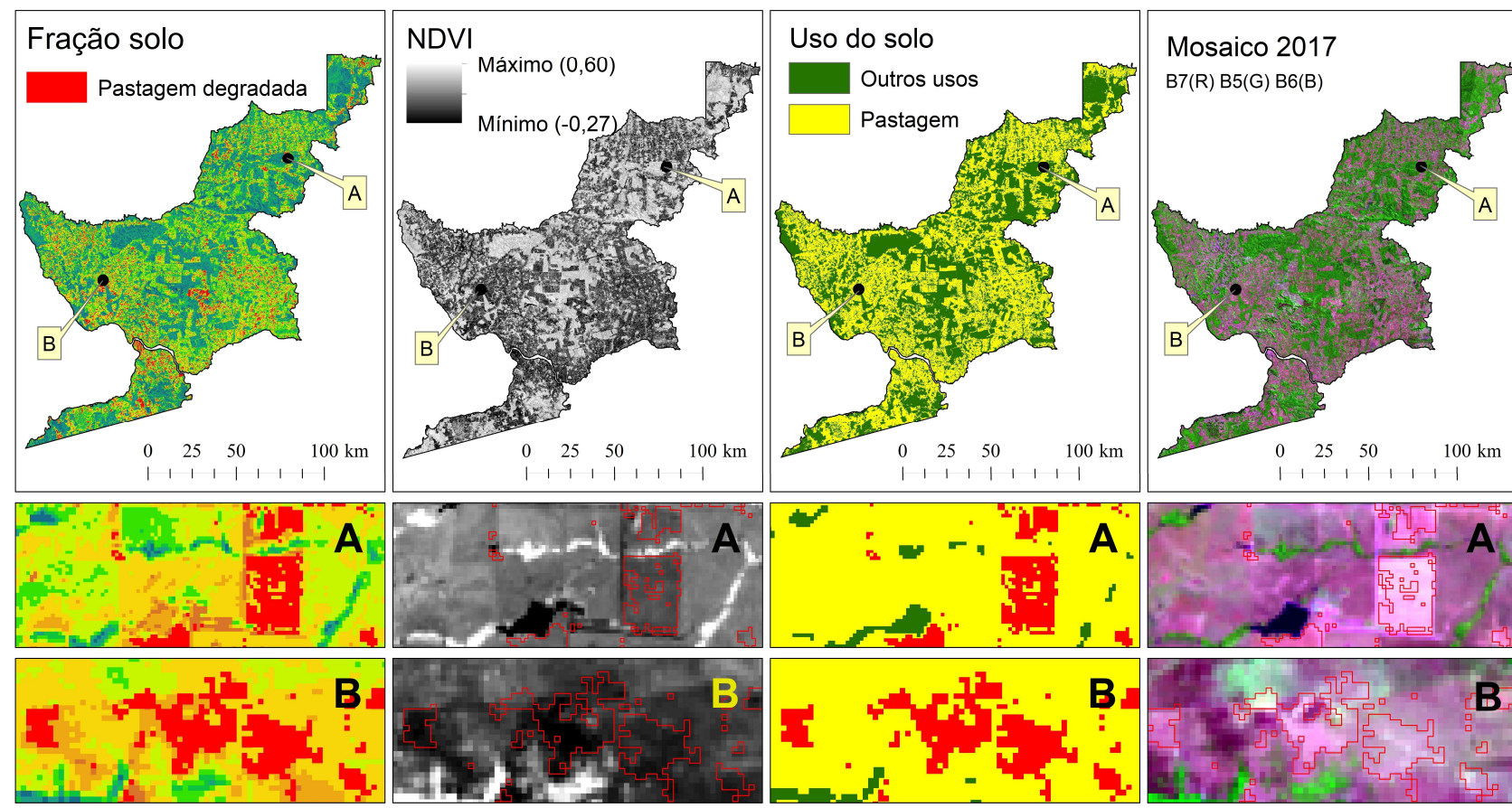

Figura 4. Verificação e interpretação visual utilizada para a identificação da amplitude de classe que melhor definiu o mapeamento de solo exposto e pastagem degradada na AC-II.

Figure 4. Visual verification and interpretation used to identify the class amplitude that best-defined exposed soil mapping and degraded pasture in AC-II.

Tabela 1. Distribuição das propriedades rurais em classes de tamanho (ha) e em classes percentuais de taxas de pastagem degradada e solo exposto.

Table 1. Distribution of rural properties in size classes (ha) and percentage classes of degraded pasture and exposed soil rates.

\begin{tabular}{rrrrrrrrrrrr}
\hline \\
\hline \multirow{2}{*}{ Classes de tamanho (ha) } & \multicolumn{4}{c}{ Classes percentuais de pastagens degradadas e solo exposto } & \multicolumn{4}{c}{ Total } \\
\cline { 2 - 12 } & $\mathrm{A}$ & $\mathrm{B}$ & $\mathrm{C}$ & $\mathrm{D}$ & $\mathrm{E}$ & $\mathrm{F}$ & $\mathrm{G}$ & $\mathrm{H}$ & $\mathrm{I}$ & $\mathrm{J}$ \\
$50-500$ & 2.843 & 104 & 28 & 14 & 9 & 1 & 3 & 1 & - & 1 & 3.004 \\
$500-1.000$ & 221 & 46 & 18 & 13 & 11 & 3 & 8 & 1 & - & 2 & 323 \\
$1.001-1.500$ & 118 & 37 & 19 & 7 & 1 & 5 & 4 & 2 & 1 & 10 & 204 \\
$1.501-2.000$ & 21 & 3 & 4 & 6 & 3 & 1 & 1 & 1 & - & - & 40 \\
$2.001-2.500$ & 12 & 2 & - & 3 & 3 & 1 & - & - & 1 & 6 & 28 \\
$2.501-3.000$ & 3 & 2 & 1 & 2 & - & - & - & 1 & 1 & 1 & 11 \\
$3.001-3.500$ & 2 & - & - & - & - & - & 1 & - & - & 1 & 4 \\
Acima 3.501 & 11 & 6 & 3 & 3 & 2 & 1 & - & 1 & - & 2 & 29 \\
\hline Total & 3.231 & 200 & 73 & 48 & 29 & 12 & 17 & 7 & 3 & 23 & 3.643 \\
\hline
\end{tabular}

Classes de taxas: A (0 a 10\%); B (10,1 a 20\%); C (20,1 a 30\%); D (30,1 a 40\%); E (40,1 a 50\%); F (50,1 a 60\%); G (60,1 a 70\%); H (70,1 a $80 \%)$; I (80,1 a $90 \%) ; \mathrm{J}(90,1$ a $100 \%)$.

\section{DISCUSSÃO}

Ao analisar a espacialização das áreas de pastagens degradadas e solo exposto foi possível notar que houve ampla distribuição na AC-II, além de somar uma área mapeada considerável (21.621 ha).

Segundo Carvalho et al. (2016), a degradação de pastagens tem sido um grande problema para a pecuária brasileira. Se bem manejadas e utilizadas respeitando suas características fisiológicas e exigências climáticas e de fertilidade do solo, mantêm-se produtivas por muito tempo. No entanto, estima-se que $80 \%$ dos 50 a 60 milhões de hectares de pastagens cultivadas encontram-se em algum estado de degradação, ou seja, são incapazes de sustentar os níveis de produção e qualidade exigida pelos animais. 


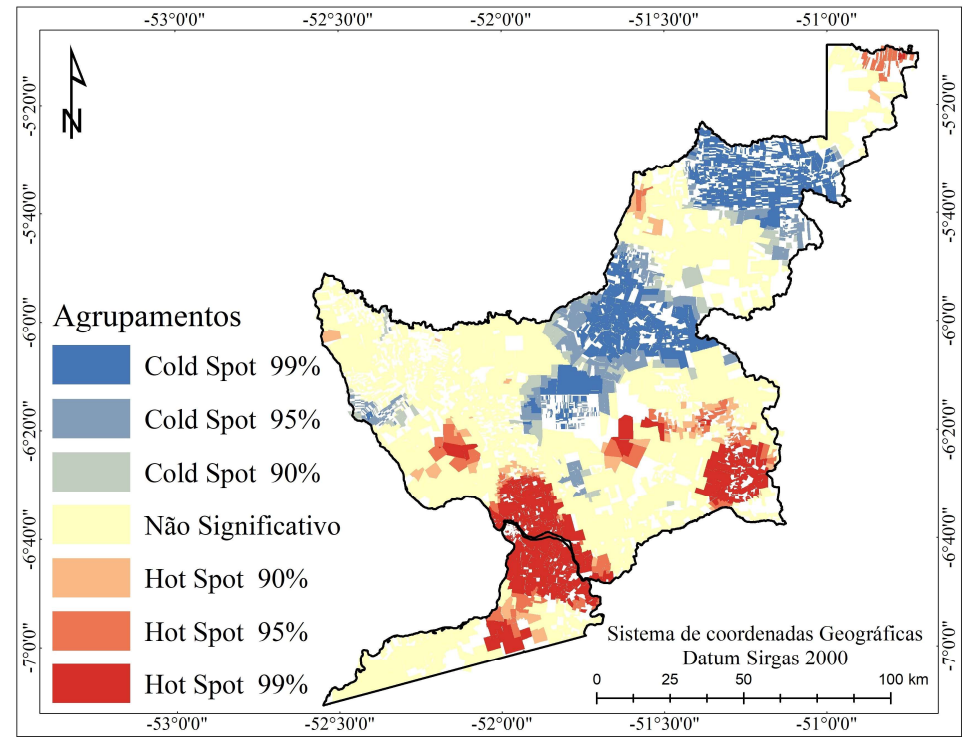

Figura 5. Agrupamento espacial hot spot para as propriedades rurais da AC-II, utilizando as taxas de pastagens degradadas e solo exposto. Figure 5. Hot spot spatial cluster for AC-II farms using degraded pasture and exposed soil rates.

Tabela 2. Distribuição das propriedades rurais em classes de tamanho (ha) e em classes percentuais de taxas de pastagem degradada e solo exposto, para os agrupamentos hot spot.

Table 2. Distribution of rural properties in size classes (ha) and percentage classes of degraded pasture and exposed soil rates for hot spot clusters.

\begin{tabular}{|c|c|c|c|c|c|c|c|c|c|c|c|}
\hline \multirow{2}{*}{ Classes de tamanho (ha) } & \multicolumn{11}{|c|}{ Classes percentuais de pastagens degradadas e solo exposto } \\
\hline & A & $\mathrm{B}$ & $\mathrm{C}$ & $\mathrm{D}$ & $\mathrm{E}$ & $\mathrm{F}$ & G & $\mathrm{H}$ & $\mathrm{I}$ & $\mathrm{J}$ & Total \\
\hline $0-500$ & 802 & 50 & 11 & 8 & 3 & 2 & 1 & - & - & 1 & 878 \\
\hline $500-1.000$ & 50 & 4 & - & - & - & - & - & - & - & - & 54 \\
\hline $1.001-1.500$ & 26 & 4 & - & 1 & - & - & - & - & - & - & 31 \\
\hline $1.501-2.000$ & 3 & - & - & - & - & - & - & - & - & - & 3 \\
\hline $2.001-2.500$ & 7 & - & 1 & - & - & - & - & - & - & - & 8 \\
\hline $2.501-3.000$ & 4 & - & - & - & - & - & - & - & - & - & 4 \\
\hline Acima 3.001 & 4 & - & - & - & - & - & - & - & - & - & 4 \\
\hline Total & 896 & 58 & 12 & 9 & 3 & 2 & 1 & 0 & 0 & 1 & 982 \\
\hline
\end{tabular}

Classes de taxas: A (0 a 10\%); B (10,1 a 20\%); C (20,1 a 30\%); D (30,1 a 40\%); E (40,1 a 50\%); F (50,1 a 60\%); G (60,1 a 70\%); H (70,1 a
$80 \%)$; I (80,1 a $90 \%)$; J (90,1 a 100\%).

Segundo Dias-Filho (2016), apesar da inegável importância das pastagens nos sistemas pecuários brasileiros, cerca de $80 \%$ das pastagens cultivadas se encontram em algum estádio de degradação ou mesmo em áreas com solos degradados, o que implica no aparecimento de pragas e plantas invasoras, diminuição da capacidade suporte, e consequente redução da produtividade do sistema.

Esse descaso com as áreas de pastagens é histórico e deriva de uma mentalidade extrativista ainda apresentada pela maioria dos pecuaristas que consideram o bovino, como reserva de capital e a bovinocultura como atividade que tem como objetivo principal a posse da terra (VEIGA et al., 2004).

A implantação de um programa de recuperação numa escala regional é dificultada pela inexistência de mapeamentos atualizados e precisos de pastagens cultivadas, seus diferentes níveis de degradação e quais os perfis de propriedades rurais envolvidas (SANO et al., 2001). Segundo Wood et al. (2015), ao abordar a pecuária, uso da terra e desmatamento na Amazônia, os autores entenderam que as propriedades rurais que possuíam mais de 500 ha, especializados em bovinos de corte, poderiam ser consideradas grandes produtores. Já as propriedades menores que 500 ha eram consideradas pequenas propriedades.

Tal fato permite considerar que o perfil de propriedades com pastagens degradadas e solo exposto na área de estudo está na categoria de pequenas propriedades rurais. Este cenário evidencia ainda mais o tipo de colonização presente até os dias atuais em SFX, predominantemente por pequenas propriedades rurais (WOOD et al., 2015, FERREIRA et al., 2005). Embora não seja possível assegurar que as pequenas propriedades foram responsáveis pela maioria das mudanças ocorridas na paisagem da área estudada, o fato é que grandes propriedades $(>1.000 \mathrm{ha})$ são relativamente mais efetivas na preservação de remanescentes e essenciais em estratégias para a conservação da biodiversidade (RICHARDS; VANWELY, 2016).

\section{CONCLUSÕES}

O mapeamento e a quantificação das áreas de pastagens degradadas e solo exposto possibilitaram importantes abordagens. Uma delas foi verificar a ocorrência de agrupamentos espaciais para as taxas de pastagens degradadas e solo exposto, e a outra foi concluir que as pequenas propriedades rurais, com até 500 ha, estão majoritariamente nesses agrupamentos. 


\section{REFERÊNCIAS}

ALMEIDA, C. A.; COUTINHO, A. C.; ESQUERDO, J. C. D. M.; ADAMI, M.; VENTURIERI, A.; DINIZ, C. G.; DESSAY, N.; DURIEUX, L.; GOMES, A. R. High spatial resolution land use and land cover mapping of the Brazilian Legal Amazon in 2008 using Landsat-5/TM and MODIS data. Acta Amazônica, Manaus, v. 46, n. 3, p. 291-302, 2016. DOI: https://doi.org/10.1590/18094392201505504

CARVALHO, T. S.; MAGALHÃES, A. S.; DOMINGUES, E. P. Desmatamento e contribuição econômica da floresta na Amazônia. Estudos Econômicos, São Paulo, v. 46, n. 2, p. 499-531, 2016. DOI: https://doi.org/10.1590/0101-416146288tae

CHANDER, G.; MARKHAM, B. L.; HELDER, D. L. Summary of current radiometric calibration coefficients for Landsat MSS, TM, ETM+, and EO-1 ALI sensors. Remote Sensing of Environment, v. 113, n. 5, p. 893903, 2009.

DOI https://doi.org/10.1016/j.rse.2009.01.007

CHEN, J.; YANG, S.; LI, H.; ZHANG, B.; LV, J. Research on geographical environment unit division based on the method of natural breaks (Jenks). The International Archives of the Photogrammetry. Remote Sensing and Spatial Information Sciences, v.XL, p.47-50, 2013.

COSTA, B. O. Degradação Florestal por extração seletiva e fogo na Amazônia Legal. Tese de Doutorado (Ciências Florestais). Universidade de Brasília, Brasília, DF, 2017, 186p.

DIAS, P.; PELEGRINA, M. A.; BERTOTTI, L. G. Análise exploratória de estatística espacial aplicada ao espaço urbano. Ambiência, Guarapuava, v. 12, n. 2, p. 539-549, 2016.

DIAS-FILHO, M. B. Uso de Pastagens para a Produção de Bovinos de Corte no Brasil: Passado, Presente e Futuro. Belém: Embrapa Amazônia Oriental, 2016. 41p.

DIAS-FILHO, M. B. Diagnóstico das pastagens no Brasil. Belém: Embrapa Amazônia Oriental, 2014, 36p.

DIAS-FILHO, M. B. Os desafios da produção animal em pastagens na fronteira agrícola brasileira. Belém, PA: Embrapa Amazônia Oriental, 2012. 34p.

FERRAZ, J. B. S.; FELÍCIO, P. E. Production systems - An example from Brazil. Meat Science, Barking, v. 84, n. 2, p. 238-243, 2010.2009 DOI: https://doi.org/10.1016/j.meatsci.2009.06.006

FERREIRA, L. V.; VENTICINQUE, E.; ALMEIDA, S. O desmatamento na Amazônia e a importância das áreas protegidas. Estudos Avançados, São Paulo, v. 19, n. 53, p. 157-166, 2005. DOI: https://doi.org/10.1590/S010340142005000100010

IBGE_Instituto Brasileiro de Geografia e Estatística. Produção da Pecuária Municipal - PPM. Indicadores do IBGE, Rio de Janeiro/RJ, v.45, p.1-17, 2018.

INPE_Instituto Nacional de Pesquisas Espaciais (INPE). PRODES Digital, Monitoramento da Floresta Amazônica Brasileira por Satélite. Taxas anuais de desmatamento na Amazônia Legal Brasileira (AML). São José dos Campos, 2018.

KAWAKUBO, F. S.; MORATO, R. G.; LUCHIARI, A. Mapeamento do desmatamento em São Félix do Xingu utilizando composição colorida multitemporal de imagens frações sombra. Anpege, Rio Verde, v. 9, n. 11, p.

119-133,

2013.

DOI: https://doi.org/10.5418/RA2013.0911.0010

LEAL, F. A.; SOUZA, C. M.; LEAL, G. S. A. Utilização do NDVI na análise da vegetação após ocorrência de incêndio. Nativa, Sinop, v. 7, n. 2, p. 226-231, 2019a. DOI: http://dx.doi.org/10.31413/nativa.v7i2.6664

LEAL, F. A.; SOUZA, F. F. B.; LEAL, G. S. A. Zoneamento de riscos de incêndios florestais em regiões hot spot de focos de calor no estado do Acre. Nativa, Sinop, v. 7, n. 3, p. 274-283, 2019b. DOI: http://dx.doi.org/10.31413/nativa.v7i3.6768

MELO, N. G. R.; ARTAXO, P. Evolução do plano de ação para prevenção e controle do desmatamento na Amazônia Legal. Instituto de Estudos Brasileiros, São Paulo, v. 8, n. 16, p. 20-45, 2017. DOI: https://doi.org/10.11606/issn.2316-901x.v0i66p108129.

MORAN, P. A. P. Notes on continuous stochastic phenomena. Biometrika, v. 37, p. 17-23, 1950.

NASCIMENTO, I. S.; CRUZ, C. B. M.; NEVES, S. M. A. S.; GALVANIN, E. A. S. Avaliação da exatidão dos classificadores Maxver e Iso Cluster do software ArcGis for desktop, com uso de imagem Landsat 8 do município de Cáceres/MT, Revista Continentes, Rio de Janeiro, v. 5, n. 8, p. 48-62, 2016.

RICHARDS, P. D.; VANWEY, L. Farm-scale distribution of deforestation and remaining forest cover in Mato Grosso. Nature Climage Change, v. 6, n. 4, p. 418-425, 2016. DOI: https://doi.org/10.1038/nclimate2854

ROCHA, J.; HENRIQUES, C. A importância da análise espacial na reconstituição da oferta educativa em Portugal. Interacções, Santarém-Portugal, v. 10, n. 28, p. 21-30, 2014. DOI: https://doi.org/10.25755/int.3909

ROUSE, J. W.; HAAS, R. H.; SCHELL, J. A.; DEERING, D. W.; HARLAN, J. C. Monitoring the Vernal Advancement of Retrogradation (Green Wave Effect) of Natural Vegetation. Greenbelt, Maryland, USA: NASA/GSFC, 1973, 390p.

SANO, E. E.; BARCELlOS, A. O.; BEZERA, H. S. Assessing the spatial distribution of cultivated pastures in the Brazilian Savanna. Pasturas Tropicales, v. 22, n. 3, p. 2-15, 2001.

SHIMABUKURO, Y. E.; PONZONI, F. J. Mistura espectral: modelo linear e aplicações. São Paulo: Editora: Oficina de Texto, 2017. 127p.

SHIMABUKURO, Y. E.; SMITH, J. A. Fraction images derived from Landsat TM/MSS data for monitoring reforested areas. Canadian Journal of Remote Sensing, v. 21, n. 1, p. 67-74, 1995. DOI: https://doi.org/10.1080/07038992.1995.10874599

SHIMABUKURO, Y. E.; SMITH, J. A. The least-squares mixing models to generate fraction images derived from remote sensing multispectral data. IEEE Transactions on Geoscience and Remote Sensing, v. 29, n. 1, p. 1620, 1991. DOI: https://doi.org/10.1109/36.103288

TIAN, Y.; SUN, C. A spatial differentiation study on comprehensive carrying capacity of the urban agglomeration in the Yangtze River Economic Belt. Regional Science and Urban Economics, Amsterdam, v. 68, p. 11-22, 2018. DOI: https://doi.org/10.1016/j.regsciurbeco.2017.10.014

VEIGA, J. B.; TOURRAND, J. F.; PIKETTY, M. G.; POCCARD-CHAPUIS, R.; ALVES, A. M. Expansão e 
Trajetórias da Pecuária na Amazônia. Brasília: UnB, $1^{\mathrm{a}}$ ed., 2004. 184p.

WOOD, C. H.; TOURRAND, J. F.; TONI, F. Pecuária, uso da terra e desmatamento na Amazônia: um estado comparativo do Brasil, do Equador e do Peru. Brasília: Editora Universidade de Brasília, 2015. 284p.

YUE, J.; TIAN, Q.; TANG, S.; XU, K.; ZHOU, C. A dynamic soil endmember spectrum selection approach for soil and crop residue linear spectral unmixing analysis. International Journal of Applied Earth Observation and Geoinformation, Enschede, v. 78, p. 306-317, 2019. DOI: https://doi.org/10.1016/j.jag.2019.02.001

ZEE. Zoneamento Ecológico-Econômico das Zonas Leste e Calha Norte do Estado do Pará: Gestão Territorial - Diretrizes de Uso e Ocupação. Belém, PA: Núcleo de Gerenciamento do Programa Pará Rural, vol. 3, 2010. 510p. 